\title{
Does mini-implant-supported rapid maxillary expansion cause less root resorption than traditional approaches? A micro-computed tomography study
}

Rukiye Alcin ${ }^{\mathrm{a}}$ (1)
Siddik Malkoç ${ }^{\mathrm{b}}$ (i)

${ }^{a}$ Private Practice, Adana, Turkey

${ }^{\mathrm{b}}$ Private Practice, lstanbul, Turkey

\begin{abstract}
Objective: This study aimed to evaluate the volume, amount, and localization of root resorption in the maxillary first premolars using micro-computed tomography (micro-CT) after expansion with four different rapid maxillary expansion (RME) appliances. Methods: In total, 20 patients who required RME and extraction of the maxillary first premolars were recruited for this study. The patients were divided into four groups according to the appliance used: miniimplant-supported hybrid RME appliance, hyrax RME appliance, acrylic-bonded RME appliance, and full-coverage RME appliance. The same activation protocol (one activation daily) was implemented in all groups. For each group, the left and right maxillary first premolars were scanned using micro-CT, and each root were divided into six regions. Resorption craters in the six regions were analyzed using special CTAn software for direct volumetric measurements. Data were statistically analyzed using Kruskal-Wallis one-way analysis of variance and Mann-Whitney $U$ test with Bonferroni adjustment. Results: The hybrid expansion appliance resulted in the lowest volume of root resorption and the smallest number of craters $(p<0.001)$. In terms of overall root resorption, no significant difference was found among the other groups $(p>0.05)$. Resorption was greater on the buccal surface than on the lingual surface in all groups except the hybrid appliance group $(p<0.05)$. Conclusions: The findings of this study suggest that all expansion appliances cause root resorption, with resorption craters generally concentrated on the buccal surface. However, the mini-implant-supported hybrid RME appliance causes lesser root resorption than do other conventional appliances.
\end{abstract}

[Korean J Orthod 2021;51(4):241-249]

Key words: Rapid maxillary expansion, Micro-computed tomography, Root resorption

Received May 19, 2020; Revised December 24, 2020; Accepted December 31, 2020.

Corresponding author: Siddik Malkoç.

Private Practice, Sarıgazi Mah. Osmangazi Cad. No: 12, Sancaktepe, Istanbul 34887, Turkey.

Tel +90-216-621-22-21 e-mail siddikmalkoc@yahoo.com

How to cite this article: Alcin R, Malkoç S. Does mini-implant-supported rapid maxillary expansion cause less root resorption than traditional approaches? A micro-computed tomography study. Korean J Orthod 2021;51:241-249.

(C) 2021 The Korean Association of Orthodontists.

This is an Open Access article distributed under the terms of the Creative Commons Attribution Non-Commercial License (http://creativecommons.org/licenses/by-nc/4.0) which permits unrestricted non-commercial use, distribution, and reproduction in any medium, provided the original work is properly cited. 


\section{INTRODUCTION}

Rapid maxillary expansion (RME) is the main treatment modality for maxillary deficiency. This technique involves the application of heavy forces on the teeth and supporting structures. While RME facilitates opening of the medial palatal suture and expansion of the maxilla, it has some undesirable effects. Histological and radiography studies have shown that the heavy forces applied by RME appliances' induce and cause external root resorption on the anchor teeth. ${ }^{2-7}$ Clinicians can use various RME appliances to widen the maxilla, such as tooth-borne and tooth-tissue-borne banded or bonded appliances..$^{1-9}$ In previous studies, conventional RME appliances were compared with hyrax, Haas, and cap splint appliances in terms of root resorption. ${ }^{2,3-7,10}$ However, the difference in tooth resorption between tooth-borne and tooth and tissue-borne appliances remains unclear. of late, mini-implant-supported RME appliances are being commonly used to minimize tipping and the undesirable effects of conventional expansion on the teeth. The first molars and palatal rugae area are usually selected as the posterior and anterior anchorage units, respectively, because of the insufficiency of appropriate bone in the posterior region. ${ }^{11}$ However, studies comparing the amount of root resorption between mini-implantsupported hybrid RME appliances and conventional appliances are limited. ${ }^{7-12}$

Root resorption can be quantitatively assessed using histological and radiographic assessments. However, two-dimensional (2D) radiographic techniques only allow measurement of the amount of root apex loss and are highly inaccurate because of magnification errors. Meanwhile, histological studies are technique-sensitive; moreover, the loss of material during histological sectioning decreases the reliability of the quantitative measurement of root resorption. ${ }^{13}$ However, there have been several developments in three-dimensional (3D) imaging techniques, and the examination of resorption craters in 3D configurations with high dimensional resolutions has become possible with the use of micro-computed tomography (micro-CT). Moreover, computer software facilitates high-precision volumetric measurement of root resorption craters. ${ }^{13}$ Micro-CT has been used as an imaging and evaluation technique in different fields of dentistry, ${ }^{14-18}$ including orthodontics, where it is used to investigate root resorption associated with tooth movement. ${ }^{13,14}$ However, to the best of our knowledge, no study has evaluated root resorption caused by different RME appliances using micro-CT.

Therefore, the aim of this study was to evaluate the root resorption volume and the amount of root resorption craters on the maxillary first premolars using micro-CT after expansion using mini-implant-supported hybrid, hyrax, acrylic-bonded, and full-coverage appliances.

\section{MATERIALS AND METHODS}

This blinded, randomized clinical study was conducted in the Department of Orthodontics at Inönü University. The study was approved by the human ethics committee of Inönü University (2014/23). The informed consents were obtained from patients. Twenty patients ( 12 female and eight male) aged 12-15 years were selected (Table 1). All patients showed maxillary constriction, maxillary tooth crowding, and orthodontic indications for both RME and extraction of the first premolars. Patients with any systemic disease, craniofacial anomalies, parafunctional habits, bruxism, a history of trauma, and/or fillings or endodontic treatment in the maxillary premolars were excluded. Randomization was performed using prepared random number tables at the start of the study. One researcher evaluated the patients while another enrolled them. The 20 enrolled patients were divided into four groups ( $\mathrm{n}=5$ each) according to the appliance used for expansion: mini-implant-supported hybrid, hyrax, acrylic-bonded, and full-coverage appliances. In each group, the left and right maxillary first premolars (10 premolars per group) were evaluated.

Table 1. Distribution of the patients according to groups, mean and standard deviation of the age and activation amount

\begin{tabular}{lcccc}
\hline \multicolumn{1}{c}{ Group } & Patient & Sample & Age (yr) & Activation (turns) \\
\hline Hybrid & 5 & 10 & $12.9 \pm 3.9$ & $33.7 \pm 7.2$ \\
Hyrax & 5 & 10 & $13.8 \pm 0.5$ & $34.2 \pm 3.3$ \\
Acrylic bonded & 5 & 10 & $14.1 \pm 0.8$ & $34.6 \pm 4.7$ \\
Full coverage & 5 & 10 & $14.2 \pm 0.6$ & $36.6 \pm 6.5$ \\
$p$-value & & & 0.589 & 0.735 \\
\hline
\end{tabular}

Values are presented as number only or mean \pm standard deviation.

According to the Kruskal-Wallis one-way analysis of variance test, there is no statistically significant intergroup difference in the mean age and number of activations. 

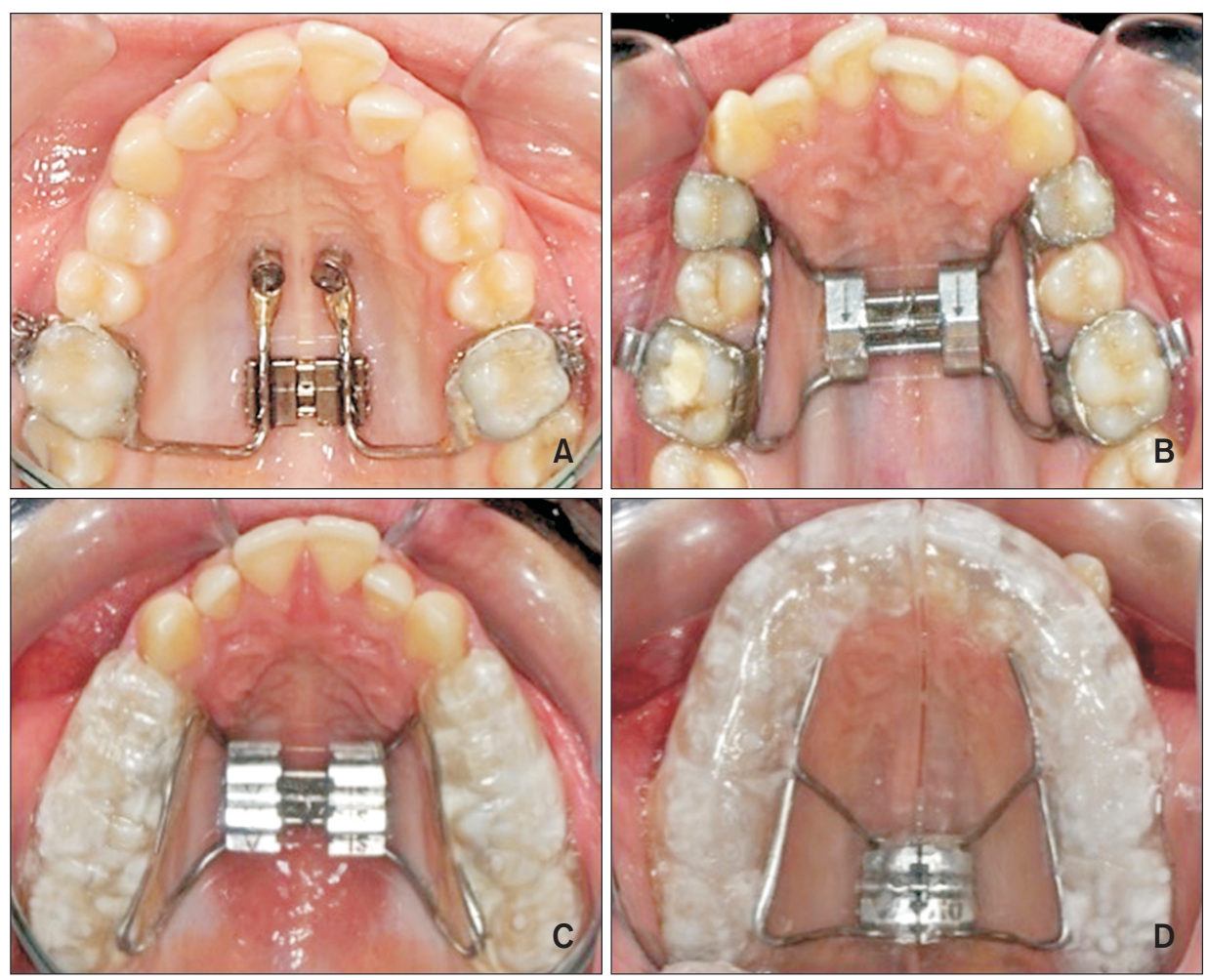

Figure 1. The four rapid maxillary expansion appliances used in this study. A, Miniimplant-supported hybrid appliance. B, Hyrax appliance. C, Acrylic-bonded appliance. D, Full-coverage appliance.

In the hybrid group (Figure 1A), two $2 \times 9$-mm miniscrews (Benefit; PSM, Tuttlingen, Germany) were bilaterally inserted into the anterior palate, perpendicular to the second and third palatal rugae and approximately 2-3 $\mathrm{mm}$ paramedian to the suture. Bands (3M Unitek, Monrovia, CA, USA) fitted to the maxillary first molars and laboratory abutments were attached to the miniscrew heads. The rings (PSM) of two standard Benefit systems were screwed onto the laboratory analogs on the cast. Hyrax screws and bands and hyrax ring connections were created by laser welding. The hybrid appliance was bonded to the teeth with a multi-cure glass ionomer cement (Ketac Cem; 3M ESPE, St Paul, MN, USA). In the hyrax group, the expansion appliance was used with bands on the first premolars and first molars (Figure 1B). In the acrylic-bonded group, a bonded expansion appliance with acrylic coverage was used. The acrylic part of the appliance extended over the occlusal and middle thirds of the vestibular surfaces of all posterior teeth (Figure 1C). In the full-coverage group, a modified (tooth-tissue-borne and full occlusal coverage) bonded acrylic cap splint RME appliance was used (Figure 1D).

The hyrax, acrylic-bonded, and full-coverage expansion appliances were bonded to the teeth with a glass ionomer luting cement (Ketac Cem; 3M ESPE). Each appliance was activated once daily until the desired expansion was achieved. Active treatment was followed by a 3-month retention period for all patients. The RME procedure was successfully completed in all patients. After the retention phase, a single oral surgeon extracted the left and right premolars of all patients in the Oral Surgery Department. The teeth were washed with isotonic solution without applying pressure on or touching the root surfaces. Then, they were disinfected in $70 \%$ alcohol for 30 minutes. The teeth were stored in sterile tubes containing distilled water.

\section{Micro-CT analysis}

All samples were scanned with an X-ray desktop microtomographer (SkyScan 1172; Bruker, Kontich, Belgium). The micro-CT system was set to $100 \mathrm{kV}$ and $100 \mathrm{~mA}$ with the aid of a $0.5-\mathrm{mm} \mathrm{Al}+\mathrm{Cu}$ filter. During scanning, the tooth was rotated $360^{\circ}$ around its vertical axis, with a single rotation step at 0.40 . The scanned data were transformed into images using NRecon (version 1.6.9.4, SkyScan). Then, the reconstructed 3D images were viewed and processed using the data analysis software CTAn (version 1.13.5.1, SkyScan). The resorption crater volumes on the root surface were analyzed in six regions. The entire root surface was vertically divided into three sections: cervical, middle, and apical. Each section was then divided into two sub-regions: buccal and lingual (Figure 2). The six regions were termed buccal cervical, lingual cervical, buccal middle, lingual middle, buccal apical, and lingual apical. In the recon- 
structed 3D images of each sample, cross-sectional images showing entire resorption craters on the buccal or lingual surface of the tooth were located (Figure 3). Then, a region of interest was drawn for each sampled image. In the second phase, the threshold of the lesion density was defined. Finally, through custom processing, the lesion depth on each selected image was measured.

\section{Statistical analysis}

To determine the sample size for each group, a power analysis was conducted on the basis of an alpha significance level of 0.05 and a beta value of 0.1 to achieve
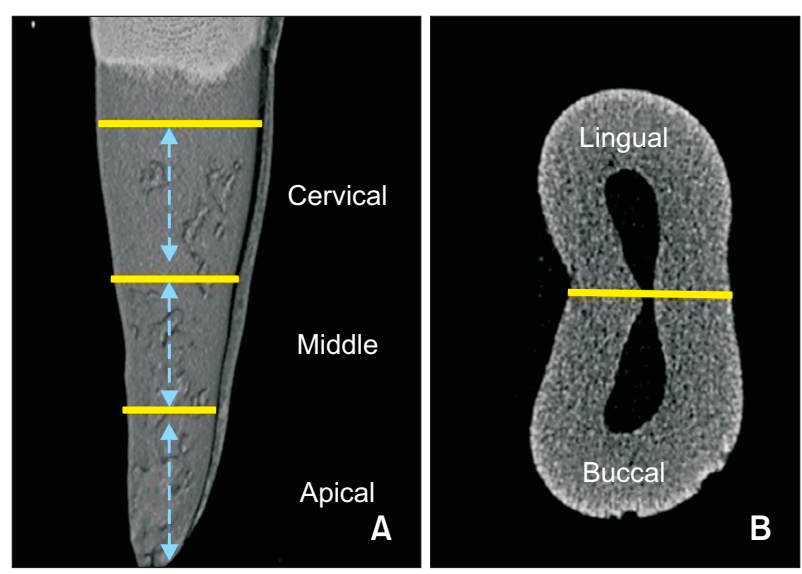

Figure 2. Representative micro-computed tomography image of a maxillary first premolar extracted after rapid maxillary expansion. The root is divided into three sections (cervical, middle, and apical) vertically $(\mathrm{A})$ and two sections horizontally (buccal and lingual) (B).
$80 \%$ power to detect an average difference of $0.5 \pm 0.20$ $\mathrm{mm}^{3}$ in the volume of resorption craters among the different groups (version 3.0.10, G*Power; Franz Faul Universidad, Kiel, Germany). ${ }^{14}$ The power analysis showed that at least eight samples per group were required. Accordingly, five patients (10 maxillary first premolars) were allocated to each group.

Data are presented as mean and standard deviation and were analyzed using SPSS software ver. 22.0 (IBM Corp., Armonk, NY, USA). Nonparametric statistical tests were conducted to determine the volume and number of resorption craters. The Kruskal-Wallis one-way analysis of variance test and the Mann-Whitney $U$ test with Bonferroni correction were used for statistical assessments. A $p$-value of $<0.05$ was considered statistically significant.

\section{RESULTS}

Descriptive data pertaining to the age of patients and number of activations of the appliances in the different groups are shown in Table 1; there were no significant intergroup differences in these parameters $(p>0.05)$. Total, buccal, and lingual volumes of root resorption in the different groups are presented in Table 2. Among all the groups, the hybrid group showed the smallest root resorption volumes, with a significant difference from the volumes in the other groups $(p<0.001)$. However, there were no significant differences in the total resorption crater volume among the hyrax, acrylic-bonded, and full-coverage groups $(p>0.05)$. Furthermore, with regard to numerical values, the total volume of root resorption was smaller with the tooth-tissue-borne full-

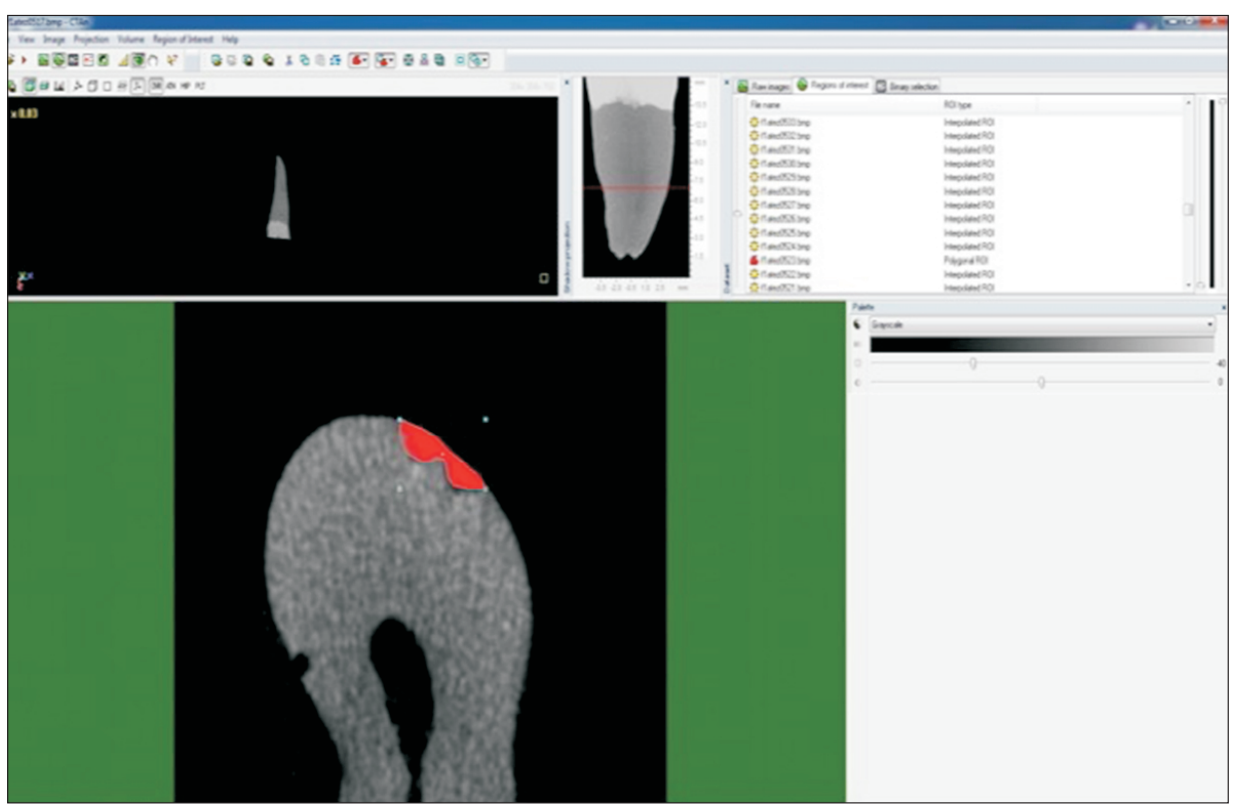

Figure 3. The use of CTAn 1.15.4.0 (SkyScan; Bruker, Kontich, Belgium) software for the isolation of a resorption crater, caused by a rapid maxillary expansion appliance, on the root surface. 
Table 2. Comparisons of root resorption volumes $\left(\mathrm{mm}^{3}\right)$ among the groups and between buccal and lingual surfaces

\begin{tabular}{lcccc}
\hline \multicolumn{1}{c}{ Group } & Buccal & Lingual & Total & p-value $^{\ddagger}$ \\
\hline Hybrid & $0.008 \pm 0.014^{\mathrm{a}}$ & $0.007 \pm 0.010^{\mathrm{a}}$ & $0.015 \pm 0.015^{\mathrm{a}}$ & 0.096 \\
Hyrax & $0.190 \pm 0.153^{\mathrm{b}}$ & $0.072 \pm 0.072^{\mathrm{b}}$ & $0.263 \pm 0.180^{\mathrm{b}}$ & $0.023^{*}$ \\
Acrylic bonded & $0.164 \pm 0.067^{\mathrm{b}}$ & $0.080 \pm 0.046^{\mathrm{b}}$ & $0.245 \pm 0.088^{\mathrm{b}}$ & $0.031^{* *}$ \\
Full coverage & $0.124 \pm 0.050^{\mathrm{b}}$ & $0.040 \pm 0.043^{\mathrm{b}}$ & $0.161 \pm 0.072^{\mathrm{b}}$ & $0.012^{*}$ \\
$p$-value $^{\dagger}$ & $0.0001^{* * *}$ & $0.025^{*}$ & $0.0001^{* * *}$ & \\
\hline
\end{tabular}

Values are presented as mean \pm standard deviation.

${ }^{*} p<0.05,{ }^{* *} p<0.01,{ }^{* * *} p<0.001$.

${ }^{\dagger}$ Comparisons among appliances: According to the Kruskal-Wallis one-way analysis of variance test and the Mann-Whitney $U$ test (with Bonferroni correction), there is no statistically significant difference between groups with the same letters.

${ }^{*}$ Comparisons between buccal and lingual surfaces: According to the Mann-Whitney $U$ test (with Bonferroni correction).

Table 3. Comparison of resorption volumes $\left(\mathrm{mm}^{3}\right)$ of six different surface among the groups

\begin{tabular}{lcccccc}
\hline \multicolumn{1}{c}{ Group } & Buccal cervical & Buccal middle & Buccal apical & Lingual cervical & Lingual middle & Lingual apical \\
\hline Hybrid & $0.007 \pm 0.012^{\mathrm{a}}$ & $0.000 \pm 0.001^{\mathrm{a}}$ & $0.001 \pm 0.001^{\mathrm{a}}$ & $0.002 \pm 0.004^{\mathrm{a}}$ & $0.002 \pm 0.005^{\mathrm{a}}$ & $0.001 \pm 0.002^{\mathrm{a}}$ \\
Hyrax & $0.071 \pm 0.049^{\mathrm{b}}$ & $0.090 \pm 0.124^{\mathrm{b}}$ & $0.030 \pm 0.020^{\mathrm{b}}$ & $0.034 \pm 0.050^{\mathrm{b}}$ & $0.030 \pm 0.030^{\mathrm{b}}$ & $0.009 \pm 0.010^{\mathrm{b}}$ \\
Acrylic bonded & $0.053 \pm 0.020^{\mathrm{b}}$ & $0.069 \pm 0.042^{\mathrm{b}}$ & $0.041 \pm 0.026^{\mathrm{b}}$ & $0.025 \pm 0.027^{\mathrm{b}}$ & $0.032 \pm 0.027^{\mathrm{b}}$ & $0.024 \pm 0.014^{\mathrm{c}}$ \\
Full coverage & $0.051 \pm 0.031^{\mathrm{b}}$ & $0.040 \pm 0.020^{\mathrm{b}}$ & $0.040 \pm 0.025^{\mathrm{b}}$ & $0.016 \pm 0.018^{\mathrm{b}}$ & $0.016 \pm 0.024^{\mathrm{b}}$ & $0.003 \pm 0.007^{\mathrm{a}}$ \\
$p$-value & $0.0001^{* * *}$ & $0.0001^{* * *}$ & $0.0001^{*}$ & $0.017^{*}$ & $0.0001^{* * *}$ & $0.002^{* *}$ \\
\hline
\end{tabular}

Values are presented as mean \pm standard deviation.

According to the Kruskal-Wallis one-way analysis of variance test and the Mann-Whitney $U$ test (with Bonferroni correction), there is no statistically significant difference between groups with the same letters.

${ }^{*} p<0.05,{ }^{* *} p<0.01,{ }^{* * *} p<0.001$.

Table 4. Comparison of root resorption number among the groups and between buccal and lingual surfaces

\begin{tabular}{lcccc}
\hline \multicolumn{1}{c}{ Group } & Buccal & Lingual & Total & $\boldsymbol{p}^{-v a l u e^{\ddagger}}$ \\
\hline Hybrid & $1.100 \pm 1.200^{\mathrm{a}}$ & $1.700 \pm 2.110^{\mathrm{a}}$ & $2.800 \pm 2.250^{\mathrm{a}}$ & 0.082 \\
Hyrax & $9.700 \pm 4.571^{\mathrm{b}}$ & $5.600 \pm 2.412^{\mathrm{b}}$ & $15.300 \pm 6.500^{\mathrm{b}}$ & $0.023^{*}$ \\
Acrylic bonded & $11.900 \pm 4.890^{\mathrm{c}}$ & $8.500 \pm 5.300^{\mathrm{c}}$ & $20.400 \pm 7.545^{\mathrm{c}}$ & $0.048^{*}$ \\
Full coverage $^{\mathrm{b}}$ & $9.300 \pm 1.950^{\mathrm{b}}$ & $3.900 \pm 3.250^{\mathrm{ab}}$ & $13.200 \pm 4.420^{\mathrm{b}}$ & $0.007^{* *}$ \\
-value $^{\dagger}$ & $0.0001^{* * *}$ & $0.003^{* *}$ & $0.0001^{* * *}$ & \\
\hline
\end{tabular}

Values are presented as mean \pm standard deviation.

${ }^{*} p<0.05,{ }^{* *} p<0.01,{ }^{* * *} p<0.001$.

${ }^{\dagger}$ Comparisons among appliances: According to the Kruskal-Wallis one-way analysis of variance test and the Mann-Whitney $U$ test (with Bonferroni correction), there is no statistically significant difference between groups with the same letters.

${ }^{\ddagger}$ Comparisons between buccal and lingual surfaces: According to the Mann-Whitney $U$ test (with Bonferroni correction).

coverage appliance than with the tooth-supported acrylic-bonded and hyrax appliances (Table 2). In addition, the resorption volume was greater on the buccal surface than on the lingual surface in all groups $(p<0.05)$ except the hybrid group $(p>0.05)$.

When the volume of resorption was analyzed in the six different root surface regions, the values for the buccal and lingual cervical, buccal and lingual middle, and buccal and lingual apical surfaces were found to be significantly smaller in the hybrid group than in the other groups $(p<0.001)$. Moreover, the root resorption volume for the lingual apical region was significant smaller in the hybrid and full-coverage groups than in the other groups ( $p<0.01$, Table 3 ).

The number of root resorption craters according to localization is shown in Tables 4 and 5 . Statistically significant differences were found for the hybrid and acrylic-bonded groups; the smallest and largest numbers of craters were observed in the hybrid $(p<0.001)$ and acrylic-bonded groups, respectively $(p<0.05$, Table 4$)$. 
Table 5. Comparison of resorption number of six different surface among the groups

\begin{tabular}{lcccccc}
\hline \multicolumn{1}{c}{ Group } & Buccal cervical & Buccal middle & Buccal apical & Lingual cervical & Lingual middle & Lingual apical \\
\hline Hybrid & $0.500 \pm 0.707^{\mathrm{a}}$ & $0.100 \pm 0.316^{\mathrm{a}}$ & $0.500 \pm 0.530^{\mathrm{a}}$ & $0.600 \pm 0.843^{\mathrm{a}}$ & $0.700 \pm 0.160^{\mathrm{a}}$ & $0.400 \pm 0.700^{\mathrm{a}}$ \\
Hyrax & $2.700 \pm 1.570^{\mathrm{b}}$ & $3.700 \pm 1.890^{\mathrm{b}}$ & $3.300 \pm 1.890^{\mathrm{b}}$ & $1.800 \pm 1.550^{\mathrm{b}}$ & $2.000 \pm 1.054^{\mathrm{b}}$ & $1.800 \pm 1.230^{\mathrm{b}}$ \\
Acrylic bonded & $2.500 \pm 0.971^{\mathrm{b}}$ & $4.400 \pm 2.065^{\mathrm{b}}$ & $5.000 \pm 2.830^{\mathrm{b}}$ & $2.300 \pm 1.890^{\mathrm{b}}$ & $3.700 \pm 3.164^{\mathrm{b}}$ & $2.500 \pm 1.581^{\mathrm{b}}$ \\
Full coverage & $2.400 \pm 1.505^{\mathrm{b}}$ & $4.200 \pm 1.032^{\mathrm{b}}$ & $2.700 \pm 1.830^{\mathrm{b}}$ & $1.800 \pm 1.316^{\mathrm{b}}$ & $1.400 \pm 1.840^{\mathrm{b}}$ & $0.700 \pm 0.060^{\mathrm{a}}$ \\
$p$-value & $0.001^{* * *}$ & $0.001^{* * *}$ & $0.001^{* *}$ & $0.033^{*}$ & $0.017^{* *}$ & $0.001^{* * *}$ \\
\hline
\end{tabular}

Values are presented as mean \pm standard deviation.

According to the Kruskal-Wallis one-way analysis of variance test and the Mann-Whitney $U$ test (with Bonferroni correction), there is no statistically significant difference between groups with the same letters.

${ }^{*} p<0.05,{ }^{* *} p<0.01,{ }^{* * *} p<0.001$.

Table 6. Comparison of resorption crater total volume $\left(\mathrm{mm}^{3}\right)$ and number values measured in six different regions of root surface

\begin{tabular}{lcc}
\hline \multicolumn{1}{c}{ Regions } & $\begin{array}{c}\text { Volume (root } \\
\text { resorption) }\end{array}$ & $\begin{array}{c}\text { Numbers (root } \\
\text { resortion craters) }\end{array}$ \\
\hline Buccal cervical & $0.050 \pm 0.051^{\mathrm{a}}$ & $2.290 \pm 1.660^{\mathrm{a}}$ \\
Lingual cervical & $0.021 \pm 0.031^{\mathrm{b}}$ & $1.310 \pm 1.361^{\mathrm{b}}$ \\
Buccal middle & $0.050 \pm 0.055^{\mathrm{a}}$ & $3.130 \pm 2.106^{\mathrm{c}}$ \\
Lingual middle & $0.025 \pm 0.030^{\mathrm{b}}$ & $1.840 \pm 1.670^{\mathrm{d}}$ \\
Buccal apical & $0.032 \pm 0.030^{\mathrm{c}}$ & $3.060 \pm 2.365^{\mathrm{c}}$ \\
Lingual apical & $0.013 \pm 0.015^{\mathrm{b}}$ & $1.680 \pm 1.450^{\mathrm{bd}}$ \\
$p$-value & $0.0001^{* * *}$ & $0.0001^{* * *}$ \\
\hline
\end{tabular}

Values are presented as mean \pm standard deviation.

According to the Kruskal-Wallis one-way analysis of variance test and the Mann-Whitney $U$ test (with Bonferroni correction), there is no statistically significant difference between groups with the same letters.

*** $p<0.001$.

The hybrid group showed the least number of resorption craters in the buccal cervical, lingual cervical, buccal middle, lingual middle, and buccal apical regions, with a significant difference from the other groups $(p<0.001)$. The apical lingual region showed fewer resorption craters in the hybrid and full-coverage groups than in the hyrax and acrylic-bonded groups ( $p<0.001$, Table 5).

When regional differences were evaluated, the root resorption volume and the number of craters were significantly increased in the buccal cervical, buccal middle, and buccal apical regions and decreased on the lingual surfaces of these regions ( $p<0.001$, Table 6$)$.

When the cervical, middle, and apical regions were analyzed, the differences between the cervical and middle regions were insignificant in terms of the root resorption volume $(p>0.05)$, whereas the apical region showed significantly lesser root resorption than did the cervical and middle regions $(p=0.001)$. The number of root resorption craters was significantly smaller in the cervical region ( $p<0.01$ ), with no significant difference between the apical and middle regions ( $p>0.05$, Table 6$)$.

\section{DISCUSSION}

Root resorption is an unavoidable pathological consequence of tooth movement, ${ }^{19}$ and it can be minimized if the related risk factors are defined. These risk factors are mostly patient-related biological variables or variables related to orthodontic mechanics. ${ }^{13,14,19,20} \mathrm{RME}$ is one of the most common procedures used in orthodontic treatment. When choosing the design of the RME appliance, the expected amount of root resorption and the safety of the appliance with respect to root resorption should be considered. To minimize the undesirable effects of tooth-borne and tooth-tissue-borne appliances, such as tipping, periodontal problems, and root resorption, ${ }^{8-10}$ bone-borne appliances have been introduced." The expansion forces applied by bone-borne appliances are directly transmitted to the palatal bone, and this minimizes complications. ${ }^{21}$ However, insertion of bone-supported appliances requires invasive techniques including flap surgery, risk of root infections or lesions, and asymmetrical enlargement. ${ }^{21,22}$ In recent years, mini-implants have gained popularity in the field of orthodontics because they are minimally invasive, multi-purpose, and low-cost. ${ }^{11,14}$ To minimize the invasiveness of the surgical technique, Wilmes et al. ${ }^{22}$ introduced the hybrid hyrax appliance, which includes two mini-screws as the anterior anchorage unit and the maxillary first molars as the posterior anchorage unit.

In the present study, root resorption in the first premolars was minimal when the mini-implant supported hybrid RME appliance was used. The hyrax, acrylicbonded, and full-coverage RME appliances caused greater root resorption because the forces resulting from the expansion were directly transmitted to the teeth, which were used as anchorage for these three appliances. Interestingly, root resorption was observed in all maxillary premolars, even those that were not used as 
anchorage in the hybrid appliance group, as observed in previous studies. ${ }^{3,6,7,10,12}$ We speculate that the root resorption directly occurred on the supported teeth, and that accumulated residual stresses caused resorption on the unsupported teeth. In contrast, in their scanning electron microscopy study, Barber and $\mathrm{Sims}^{4}$ did not find root resorption in premolars that were not used as anchorage for RME appliances. However, this discrepancy may have occurred because the measurement technique used by Barber and Sims ${ }^{4}$ may not be as sensitive as micro-CT measurements, and even though resorption may have occurred, it may have remained undetected.

The dental, skeletal, and periodontal effects of surgically assisted RME using hybrid and hyrax appliances have been compared using cone-beam computed tomography. ${ }^{10,12}$ Hybrid appliances were found to cause lesser periodontal damage and damage to the first molars, whereas the hyrax RME caused more dental tipping, root resorption, and buccal alveolar bone resorption. Similarly, in our study, the hybrid appliance caused less root resorption than did the hyrax and other appliances.

There are two main contrasting results reported in regard to the RME appliance type and its effect on root resorption in the literature. The first one is that there is no difference in root resorption between tooth-borne and tooth-tissue-borne appliances. ${ }^{2,8}$ The second one is that tooth-tissue-borne appliances cause less buccal root resorption than do tooth-borne appliances because the expansion forces are transmitted to not only the anchor teeth but also other supporting tissue segments connected to the appliance. ${ }^{3,6,7}$ In this study, although the difference was not statistically significant, root resorption was lesser with the tooth-tissue-borne fullcoverage appliance than with the tooth-borne acrylicbonded and hyrax appliances. Moreover, more root resorption was observed with the hyrax appliance than with the acrylic-bonded appliance. The reduced occlusal locking and interferences due to the acrylic occlusal surfaces could be a reason for the lesser resorption.

Odenrick et al. $^{3}$ suggested that removal of the force application point from teeth would lead to less root resorption. Histological studies of root resorption caused by the Haas and hyrax appliances have shown that the tissue-borne Haas appliance led to lesser buccal root resorption and smaller, shallower resorption lacunae than did the tooth-borne hyrax appliance. Meanwhile, Erverdi et al. ${ }^{2}$ found that tooth-borne and tissue-borne appliances caused comparable amounts of root resorption. However, when the distribution of resorption lacunae was analyzed, more coronal lacunae were found in the cap splint group because the tooth-supported cap splint appliance caused more tipping of the teeth with lateral forces. In the present study, both the resorption volume and the number of resorption craters were more on the buccal root surface than on the lingual root surface. Depending on the forces applied in the transverse direction during maxillary expansion, tipping of the teeth to the buccal surface creates more pressure and compression areas on the buccal surface. Therefore, the resorption craters are concentrated on the buccal surface. This finding is supported by those in previous studies showing more root resorption on the buccal surface after RME. ${ }^{2-7}$ When the resorption in the cervical, middle, and apical regions was evaluated in this study, the root resorption volume was similar in the cervical and middle regions and significantly smaller in the apical region. Moreover, note that the root surface area in the apical region is smaller because of the root morphology. Although the number of root resorption craters was significantly lower in the cervical region, no significant difference was found between the apical and middle regions. According to our micro-CT images and findings, resorption craters were wider and fewer in the cervical region and smaller and more in number in the middle region. The localization of root resorption after treatment largely depends on the type of orthodontic movement. In particular, high-pressure areas are affected more than stress areas. Under buccal tipping movements, more resorption occurs in buccal cervical and lingual apical regions. ${ }^{13,19}$ In this study, as a result of expansion, wider resorption craters may have been formed in the cervical region because of buccal tipping of the tooth axes and the concentration of stresses in the cervical region.

Conventional radiographs may be useful for the detection of severe root resorption. However, clear visualization of resorption in the mesial, distal, and middle apical regions of the root may be difficult. ${ }^{23}$ For the evaluation of root resorption, 2D conventional radiography is used as a diagnostic tool, although it is not recommended for assessment of the amount of root resorption. ${ }^{24}$ Techniques that allow a 3D view of root resorption craters can provide more accurate results. As root resorption is a 3D phenomenon, 2D methods such as conventional radiography can lead to underestimation. ${ }^{12,25,26}$ Moreover, the low resolution offered by conventional CT is not adequate for the reconstruction of small objects such as teeth, or tooth resorption. With the development of micro-CT, the vertical resolution capacity has increased to $100-200 \mu \mathrm{m}$. In recent years, the resolution increased to $81 \mu \mathrm{m}$, to $34-68 \mu \mathrm{m}$, and to 25-15 $\mu \mathrm{m}$. Currently, a resolution of less than $10 \mu \mathrm{m}$ has been achieved. ${ }^{15,16}$ A micro-CT imaging system enables high-resolution 3D imaging of mineralized tissue. The advantages of this system are as follows: no need for sample preparation for screening, no damage to the root surface during scanning, adequate reproducibility, and acquisition of volumetric data from the object being scanned. ${ }^{14,18}$

Yildirim and $\mathrm{Akin}^{7}$ conducted a very well-designed 
investigation. Although our results are similar to theirs, our methodology is very different. First, Yildirim and Akin $^{7}$ used an experimental RME appliance; one side of this modified appliance covers the teeth with acrylic, while the other side is fixed to the palatal bone with a screw. This design is not suitable for routine clinical use. In our study, we used four different RME appliances that are routinely used in clinical practice. Consequently, our findings directly reflected those expected in the clinical setting. Second, we compared four different RME appliances, while Yildirim and $\mathrm{Akin}^{7}$ only compared two RME groups.

This study had some limitations. Root resorption was remarkably low in the hybrid group; however, only the maxillary first premolars, which were indicated for extraction, were evaluated, considering micro-CT can only be used for in vitro studies. Root resorption in the molar teeth, which were used as the anchorage unit, was not analyzed. A larger sample size and other posterior teeth should be evaluated for root resorption in future studies. Nevertheless, the results suggest that although all the evaluated RME appliances cause root resorption, the mini-implant-supported hybrid appliance may be the safest in this regard.

\section{CONCLUSION}

The amount of root resorption after RME may be lesser with the mini-implant-supported hybrid appliance than with other conventional appliances. This represents a potential advantage of the former over the latter.

\section{CONFLICTS OF INTEREST}

No potential conflict of interest relevant to this article was reported.

\section{ACKNOWLEDGEMENTS}

This study was supported by the Scientific and Technological Research Institution of Turkey (TUBITAK) (No. 214S051).

\section{REFERENCES}

1. Almuzian M, Short L, Isherwood G, Al-Muzian L, McDonald J. Rapid maxillary expansion: a review of appliance designs, biomechanics and clinical aspects. Orthod Update 2016;9:90-5.

2. Erverdi N, Okar 1, Kücükkeles N, Arbak S. A comparison of two different rapid palatal expansion techniques from the point of root resorption. Am J Orthod Dentofacial Orthop 1994;106:47-51.

3. Odenrick L, Karlander EL, Pierce A, Kretschmar U.
Surface resorption following two forms of rapid maxillary expansion. Eur J Orthod 1991;13:264-70.

4. Barber AF, Sims MR. Rapid maxillary expansion and external root resorption in man: a scanning electron microscope study. Am J Orthod 1981;79:630-52.

5. Langford SR. Root resorption extremes resulting from clinical RME. Am J Orthod 1982;81:371-7.

6. Akyalcin S, Alexander SP, Silva RM, English JD. Evaluation of three-dimensional root surface changes and resorption following rapid maxillary expansion: a cone beam computed tomography investigation. Orthod Craniofac Res 2015;18 Suppl 1:117-26.

7. Yildirim M, Akin M. Comparison of root resorption after bone-borne and tooth-borne rapid maxillary expansion evaluated with the use of microtomography. Am J Orthod Dentofacial Orthop 2019;155:182-90.

8. Malkoç S, İşeri H, Durmuş E. Semirapid maxillary expansion and mandibular symphyseal distraction osteogenesis in adults: a five-year follow-up study. Semin Orthod 2012;18:152-61.

9. Orhan M, Üsümez S, Malkoç S. Modified bonded rapid maxillary expansion appliance. World J Orthod. 2003;4:119-25.

10. Dindaroğlu F, Doğan S. Evaluation and comparison of root resorption between tooth-borne and toothtissue borne rapid maxillary expansion appliances: a CBCT study. Angle Orthod 2016;86:46-52.

11. Ludwig B, Sebastian B, Bowman SJ. Mini-implants in orthodontics: innovative anchorage concepts. London: Quintessence Publishing; 2008.

12. Kayalar E, Schauseil M, Kuvat SV, Emekli U, Firatlı S. Comparison of tooth-borne and hybrid devices in surgically assisted rapid maxillary expansion: a randomized clinical cone-beam computed tomography study. J Craniomaxillofac Surg 2016;44:285-93.

13. Cheng LL, Türk T, Elekdağ-Türk $S$, Jones AS, Petocz P, Darendeliler MA. Physical properties of root cementum: part 13. Repair of root resorption 4 and 8 weeks after the application of continuous light and heavy forces for 4 weeks: a microcomputedtomography study. Am J Orthod Dentofacial Orthop 2009;136:320.e1-10; discussion 320-1.

14. Çelik Güler Ö, Malkoç S. Effects of orthodontic force on root surface damage caused by contact with temporary anchorage devices and on the repair process. Korean J Orthod 2019;49:106-15.

15. Malkoç MA, Sevimay M, Tatar İ, Çelik HH. Micro-CT detection and characterization of porosity in luting cements. J Prosthodont 2015;24:553-61.

16. Karaaslan G, Malkoc MA, Yildirim G, Malkoc S. Comparison of time-dependent two-dimensional and three-dimensional stability with micro-computerized tomography and wettability of three impression ma- 
terials. Niger J Clin Pract 2018;21:912-20.

17. Demir N, Ozturk AN, Malkoc MA. Evaluation of the marginal fit of full ceramic crowns by the microcomputed tomography (micro-CT) technique. Eur J Dent 2014;8:437-44.

18. Kucuk EB, Malkoc S, Demir A. Microcomputed tomography evaluation of white spot lesion remineralization with various procedures. Am J Orthod Dentofacial Orthop 2016;150:483-90.

19. Brezniak N, Wasserstein A. Orthodontic root resorption: a new perspective. Angle Orthod 2016;86: 1056-7.

20. Davidovitch Z, Krishnan V. Role of basic biological sciences in clinical orthodontics: a case series. Am J Orthod Dentofacial Orthop 2009;135:222-31.

21. Verstraaten J, Kuijpers-Jagtman AM, Mommaerts MY, Bergé SJ, Nada RM, Schols JG. A systematic review of the effects of bone-borne surgical assisted rapid maxillary expansion. J Craniomaxillofac Surg 2010;38:166-74.

22. Wilmes B, Nienkemper M, Drescher D. Application and effectiveness of a mini-implant- and toothborne rapid palatal expansion device: the hybrid hyrax. World J Orthod 2010;11:323-30.

23. Maltha JC, van Leeuwen EJ, Dijkman GE, KuijpersJagtman AM. Incidence and severity of root resorption in orthodontically moved premolars in dogs. Orthod Craniofac Res 2004;7:115-21.

24. Chan EK, Darendeliler MA. Exploring the third dimension in root resorption. Orthod Craniofac Res 2004;7:64-70.

25. Dudic A, Giannopoulou C, Martinez M, Montet X, Kiliaridis S. Diagnostic accuracy of digitized periapical radiographs validated against micro-computed tomography scanning in evaluating orthodontically induced apical root resorption. Eur J Oral Sci 2008;116:467-72.

26. Ericson S, Kurol J. Incisor root resorptions due to ectopic maxillary canines imaged by computerized tomography: a comparative study in extracted teeth. Angle Orthod 2000;70:276-83. 